\title{
LIPARIS VOLCANICA (ORCHIDACEAE), UNA ESPECIE NUEVA DEL OCCIDENTE DE MEXICO'
}

\author{
Roberto Gonzalez Tamayo \\ Instituto de Botánica \\ Universidad de Guadalajara \\ Apartado Postal 139 \\ 45110 Zapopan, Jalisco, México \\ SERGIO ZAMUdio \\ Instituto de Ecología \\ Centro Regional del Bajío \\ Apartado Postal 386 \\ 61600 Pátzcuaro, Michoacán, México
}

\section{RESUMEN}

Se propone como especie nueva Liparis volcanica, conocida de los estados de Nayarit, Jalisco y Michoacán y se le compara con Liparis greenwoodiana Espejo, su congénere más cercano. Las principales diferencias entre las dos especies se encuentran en la forma del labelo.

\begin{abstract}
Liparis volcanica from Nayarit, Jalisco and Michoacan states, is proposed as a new species. It is compared with Liparis greenwoodiana Espejo, its most close ally. The most important differences between these taxa are found in the form of the lip.

A mediados de noviembre de 1989, durante una excursión al Volcán Ceboruco en el estado de Nayarit, se encontraron creciendo sobre rocas algunas plantas de una especie de Liparis a punto de terminar de florecer, por lo que únicamente se colectaron unas 4 flores apicales de dos inflorescencias. Al tratar de identificarlas se vió que para la región sólo estaba registrada L. vexillifera (Llave \& Lex.) Cogn. (McVaugh, 1985), de la cual diferían por completo. Por revisiones posteriores se concluyó que las flores no pertenecían a ninguna de las especies conocidas de ese género en México, aunque parecían cercanas a L. greenwoodiana Espejo.
\end{abstract}

\footnotetext{
1 Trabajo realizado con el apoyo del Centro de Investigación y Desarrollo del Estado de Michoacán, del Consejo Nacional de Ciencia y Tecnología y de la Universidad de Guadalajara.
} 
Ese mismo año, al consultar el material depositado en el herbario de la Universidad Autónoma de Guadalajara (GUADA), se encontró un pliego con dos especímenes en perfecto estado, que a pesar de mostrar pequeñas diferencias, parecían muy afines a las plantas del Ceboruco. Sin embargo, no se quiso hacer la descripción sólo con esos ejemplares y se prefirió esperar la siguiente temporada de lluvias para obtener material vivo en cantidades suficientes.

En septiembre de 1990 se visitó de nuevo la localidad y se encontró un buen número de individuos en plena floración, de los cuales se tomaron para herborizar aquellos que representaban mejor los extremos de tamaño, con base en uno de ellos se hizo el dibujo que aparece más adelante.

A finales de septiembre de 1991 se localizó una población importante de esta especie en las paredes de una cañada dentro del bosque de Pinus oocarpa y Quercus magnoliifolia al norte de Caltzontzin, en el municipio de Uruapan, Michoacán.

Con todo este material se integró la descripción de la especie que se propone como nueva:

Liparis volcanica González-Tamayo et Zamudio, sp. nov. Fig 1.

Herba terrestris vel lithophytica, usque ad $26 \mathrm{~cm}$ alta, Liparidem greenwoodianam Espejo parum simulans. Folia 1-2, radicalia, patentia, textura membranosa, lamina suborbiculari-ovata vel ovato-lanceolata, obtusata, 3-11 cm longa, 2-6.5 cm lata. Scapus 3-4-alatus, racemus floribus laxe dispositis. Perigonium herbaceum virescens. Sepala triangulari-oblonga, 3-nervia; lateralia obliqua, mucronata, marginibus valde revolutis, 7.5$8.5 \mathrm{~mm}$ longa, 2.3-2.5 mm lata. Petala linearia, obtusa, 1-nervia, 8-8.5 mm longa, supra basim purpurea. Labellum oblongo-triangulare, reduplicatum, subobtusum, viridi-purpureum, 9-11 mm longum, 3-3.5 mm latum, intus carinatum, base sagitata vel truncata, marginibus basaliter et apicaliter crenulato-dentatis, supra basim callo subquadrato, bicornuto ornatum. Columna arcuata, base incrassata, apice alato, $4.5 \mathrm{~mm}$ longa. Pollinia 4, 2 paribus aequalibus, ovoidea.

Planta herbácea perenne, terrestre o rupícola, solitaria, de $8.5-26 \mathrm{~cm}$ de alto (incluyendo el cormo y la inflorescencia). Raíces filiformes, pubescentes, nacen de la base del cormo del año anterior. Cormo ovoide, oblicuo, 1.2-2.7 cm de largo, por 1-2 cm de ancho, cubierto completamente por los restos escariosos y fibrosos de las vainas. Hojas 1-2, la externa más grande que la interna, lámina extendida, apoyada sobre el suelo, verdeamarillenta, más o menos plana, surcado-carinada, a veces arqueada o levemente torcida, suborbicular-ovada a ovado-lanceolada, base cordada, abruptamente contraida en una vaina, ápice obtuso, de $3-11 \mathrm{~cm}$ de largo, por 2-6.5 cm de ancho. Inflorescencia escaposa, erecta, racimo laxo con 5-49 flores, $3-16 \mathrm{~cm}$ de largo, por $3-4.5 \mathrm{~cm}$ de diámetro; raquis y escapo 3-4 angulares, ángulos alados, el escapo verde en la porción basal, raquis de la inflorescencia verde o de color púrpura. Bráctea floral ascendente o subextendida, verde, angostamente-triangular a deltoide-lanceolada, acanalada, carinada hacia la base, la quilla decurrente sobre el raquis, ápice obtuso, de 5-12 $\mathrm{mm}$ de largo por 1-2 $\mathrm{mm}$ de ancho, 1-nervada. Ovario pedicelado, extendido o ascendente, levemente arqueado, un poco dilatado en el ápice, de color púrpura, 12-15 mm de largo. Flores resupinadas, verdes a verde-purpúreas, poco llamativas. Sépalo dorsal reflejo, a veces ligeramente torcido, 


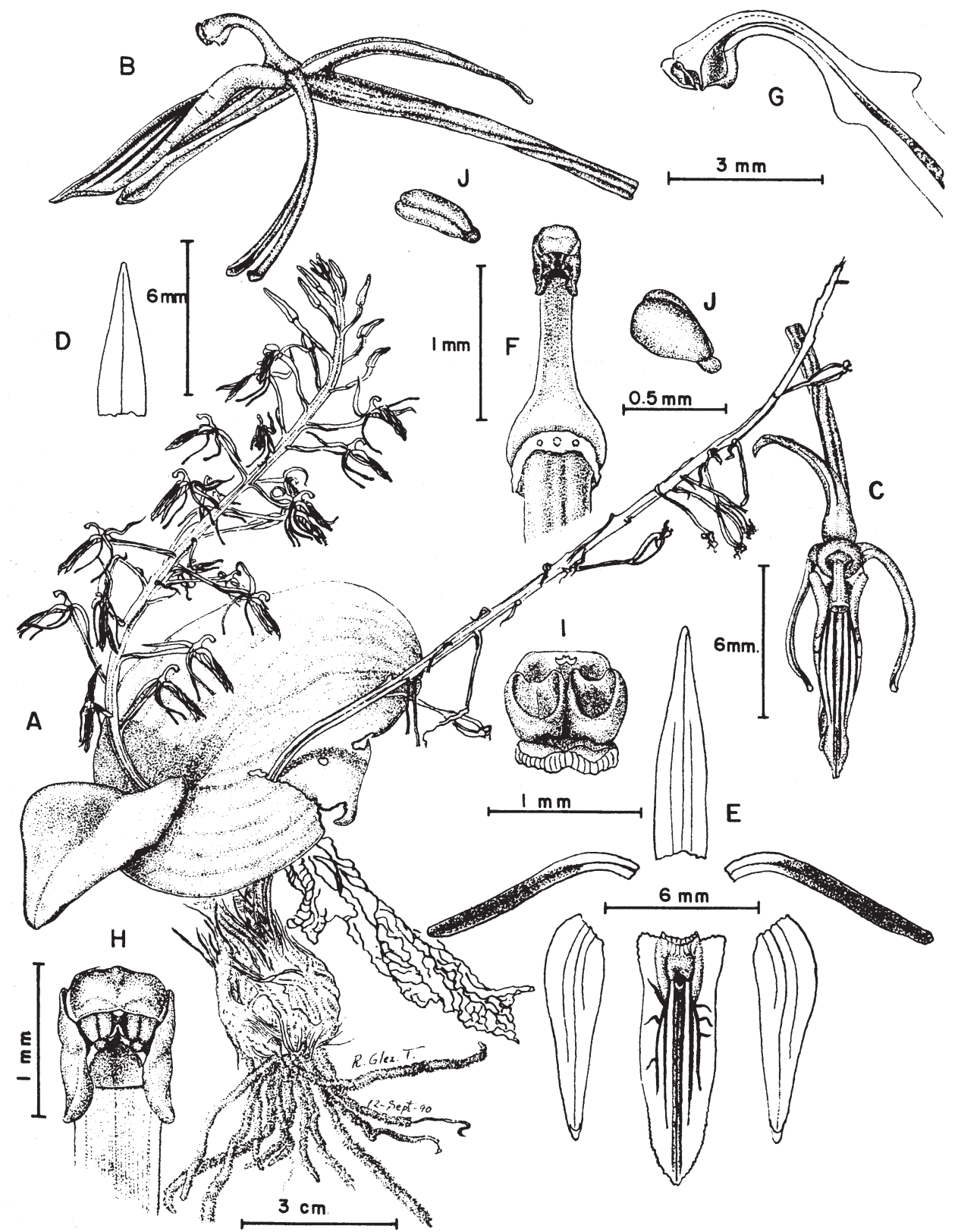

Fig. 1. Liparis volcanica González-Tamayo et Zamudio. A. Planta; B. Flor en vista lateral; C. Flor en vista frontal; D. Bráctea floral; E. Análisis floral; F. Columna en vista frontal; G. Columna en sección longitudinal; H. Parte superior de la columna; I. Antera; J. Polinias. 
arqueado, los márgenes fuertemente revolutos, verdoso, al ser extendido es oblongotriangular, ápice redondeado, incurvo, de 9-9.5 mm de largo, por $2 \mathrm{~mm}$ de ancho, 3nervado, los nervios de color púrpura. Sépalos laterales suberectos, apoyados en la cara inferior del labelo, casi paralelos a éste, torcidos, verdes, los márgenes fuertemente revolutos, cuando se extienden son oblongo-triangulares, base oblicua con el lado exterior dilatado, ápice agudo, mucronado, 5-8.5 mm de largo, por 2.3-2.5 mm de ancho. Pétalos reflejos, arqueados, ligeramente dirigidos hacia adelante, los márgenes revolutos, al ser extendidos son lineares, ápice obtuso, oblicuos en la base, 1-nervados, 8-8.5 mm de largo, por $0.8 \mathrm{~mm}$ de ancho; verdes en la base, teñidos de púrpura hacia el ápice. Labelo suberecto, reduplicado, verde, en la base presenta una cavidad pequeña sobre la que hay un callo sub-cuadrado, el cual tiene el ápice bicornudo, adelante de ella a todo lo largo está recorrido por una vena brillante, gruesa, cóncava en la base, 5-nervado, los nervios paralelos, de color púrpura, los tres centrales cercanos, llegan hasta el ápice, los nervios laterales bífidos, la rama exterior más corta, con 2 ó 3 pequeñas ramificaciones perpendiculares, más o menos equidistantes, al ser extendido es oblongo-triangular, la base sagitado-truncada, excedida por el callo, ápice agudo, conspicuamente mucronado, de 9$11 \mathrm{~mm}$ de largo, por 3-3.5 mm de ancho en la base, margen dentado-crenulado en las porciones basal y apical. Columna verde, arqueada, suberecta, carinada, abruptamente dilatada en la base, semi-cilíndrica en sección transversal, $4.5 \mathrm{~mm}$ de largo, por $2 \mathrm{~mm}$ de ancho en la base, cerca del ápice presenta dos alas incurvas, deltoides, subagudas, con el margen decurrente hacia la base, la parte superior truncada, el ápice ligeramente convexo y dirigido hacia afuera. Clinandrio cóncavo, algo profundo, oscuramente trilobado, el lóbulo medio ancho y grueso, formando el tejido dorsal de la antera; los lóbulos laterales delgados, laminares, cortos, truncados. Rostelo laminar, perpendicular al cuerpo de la columna, dorsalmente carinado, lateralmente decurrente en el estigma, algo acanaladoconduplicado, el ápice apiculado, el apículo extendido, deltoide, agudo. Estigma deltoideovado, profundamente cóncavo, la base truncada, el ápice agudo, los lados llegan a ocupar una porción de las alas de la columna, $0.6 \mathrm{~mm}$ de largo, por $0.4 \mathrm{~mm}$ de ancho. Antera incumbente, verde, subcuadrada, $0.8 \mathrm{~mm}$ de largo, por $0.8 \mathrm{~mm}$ de ancho, dorsoventralmente aplanada, el ápice truncado, en la base dorsalmente soldada al lóbulo medio del clinandrio, bilocular, las celdas cóncavas, cuculadas, redondeadas en la base, el margen romo, blanco, dorsalmente emarginadas, la escotadura redondeada, ancha, el fondo muestra apenas un vestigio de tabique. Polinario consistiendo de 4 polinias iguales dispuestas en dos pares, lateralmente aplanadas, amarillas, ovado-deltoides, cerosas, $0.4 \mathrm{~mm}$ de longitud; viscidios dos, pastosos, blancos, translúcidos, semi-esféricos, adnados a los lados del apículo del rostelo. Cápsula ascendente, oblongo-elipsoide, el ápice abruptamente contraido, así como la base que se tiñe de púrpura, $8 \mathrm{~mm}$ de largo, por $3.5 \mathrm{~mm}$ de diámetro, sostenida por un largo pedicelo torcido, de color púrpura.

Tipo: México: Michoacán, Municipio de Uruapan, 2 km al N de Caltzontzin, 1700 m, 2.IX.1991, E. Pérez \& S. Zamudio 2594 (IEB).

Material examinado: Mexico: Nayarit, Volcán Ceboruco, 1940 m, 11.IX.1990, E. Salcedo P., R. Ramirez y R. G. Tamayo s.n. (IBUG). Jalisco, Municipio Atemajac de Brizuela, 15.VIII.1987, 2200 m, C. Díaz Luna 18942 (GUADA). 
$\circlearrowleft$

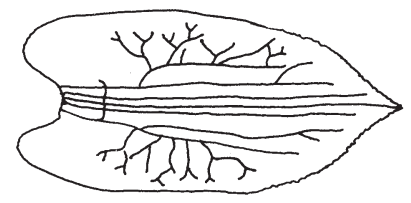

$\circlearrowleft$
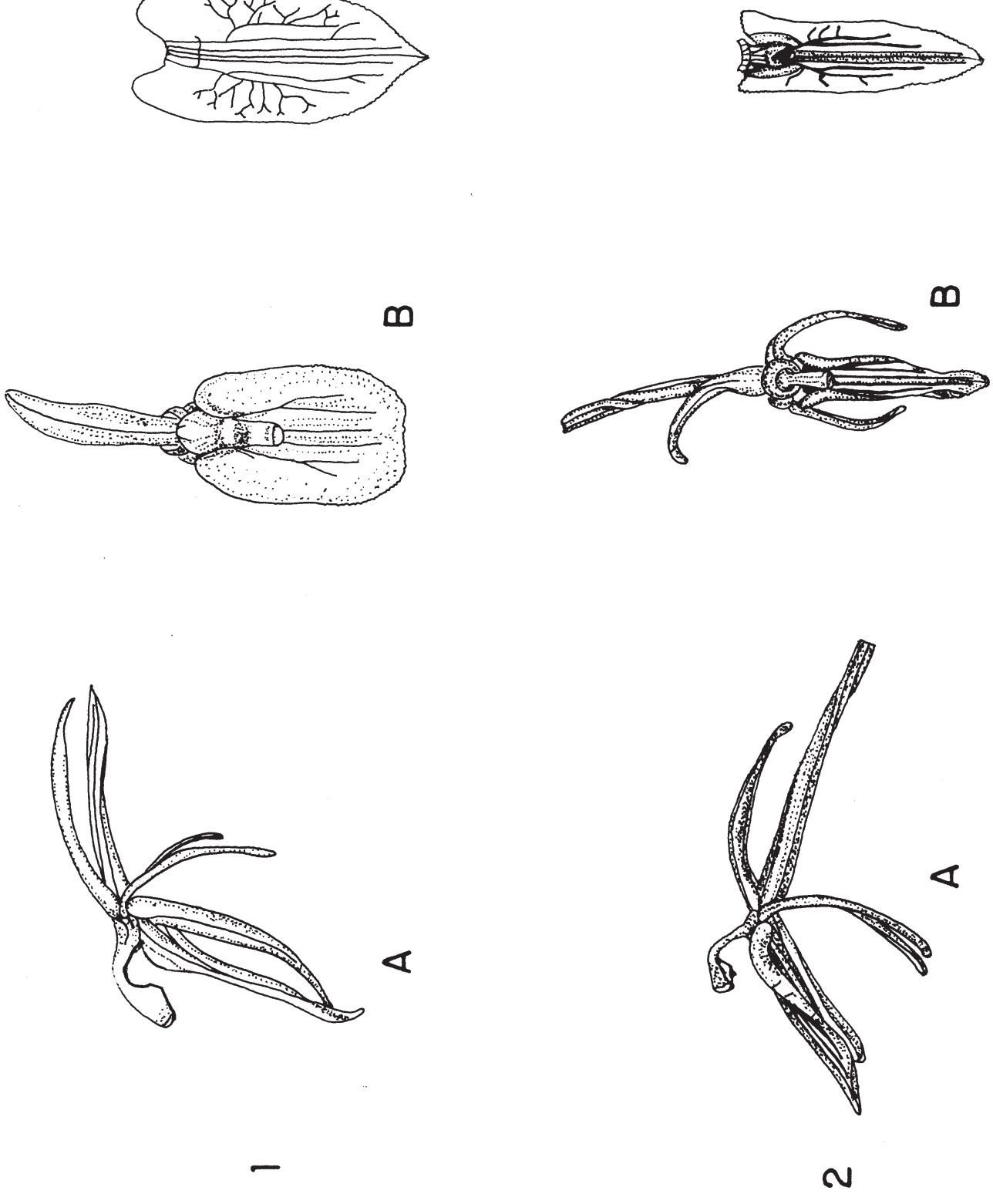

Fig. 2. Comparación entre 1. Liparis greenwoodiana Espejo y 2. Liparis volcanica González-Tamayo et Zamudio. A. Vista lateral de la flor; B. Vista frontal de la flor; C. Labelo extendido. 
Epoca de Floración: De mediados de agosto a principios de noviembre.

Habitat: Terrestre o litofítica, crece en taludes, paredes casi verticales o sobre rocas volcánicas, entre hierbas, musgos y helechos; abundante localmente en sitios húmedos bien iluminados.

Etimología: El nombre de la especie refleja su afinidad por los suelos derivados de rocas ígneas basálticas y su distribución a lo largo del Eje Volcánico Transversal.

Observaciones: El mucrón del labelo varía en flores de la misma planta, desde pequeño hasta bien desarrollado. Nótese que las vainas que forran al cormo son cortamente foliáceas. En el campo las plantas se distinguen con facilidad por sus hojas verde claro que contrastan con el color obscuro del suelo; en cambio, las flores son inconspicuas.

Distribución conocida: México: Nayarit, Jalisco y Michoacán, entre 1700 y 2200 m s.n.m.; es posible que la especie se encuentre también en otros estados en el Eje Volcánico Transversal.

Liparis volcanica es muy cercana a L. greenwoodiana, de la que se diferencia por ser una planta más delicada, pero sobre todo por sus características florales. En la primera las flores son verdes con las venas purpúreas, el labelo en posición natural es reduplicado, al ser extendido es oblongo-triangular, con la base sagitado-truncada, el ápice agudo, acuminado, con cinco venas paralelas, las laterales poco ramificadas, en algunos especímenes (C. Díaz Luna 18942) los nervios son 7; en cambio en L. greenwoodiana las flores son verdoso-purpúreas con las venas más oscuras, el labelo es de color púrpura oscuro, iridescente, extendido y plano en posición natural, elíptico-oblongo, la base cordada y el ápice agudo a acuminado, con cinco venas, las laterales muy ramificadas (Fig. 2).

\section{AGRADECIMIENTOS}

Los autores deseamos agradecer el apoyo recibido de la Profesora Luz Ma. Villarreal, Directora del Instituto de Botánica y de las autoridades de la Universidad de Guadalajara. Al Dr. Jerzy Rzedowski nuestra gratitud por la lectura y corrección del manuscrito. Al Biólogo Emmanuel Pérez Cálix y al Ingeniero Raymundo Ramírez D. nuestro reconocimiento por su entusiasta colaboración en el trabajo de campo.

\section{LITERATURA CITADA}

Espejo, A. 1987. Neotipificación de Cymbidium vexilliferum La Llave \& Lexarza (=Liparis vexillifera) y descripción de Liparis greenwoodiana. Orquídea (Méx.) 10(2): 365-384.

McVaugh, R. 1985. Flora Novo-Galiciana, Vol. 16: Orchidaceae. The University of Michigan Press. Ann Arbor, Mich. 363 pp. 